\title{
A Universidade no Brasil: das origens à Reforma Universitária de 1968
}

\section{University in Brazil: from its origins to university reform - 1968}

\author{
Maria de Lourdes de Albuquerque Fávero*
}

RESUMO

Situa as tentativas de criação de universidades no Brasil da Colônia ao Império e início da República, que não tiveram êxito. Registra a promulgação de vários dispositivos legais referentes ao ensino superior na Primeira República, embora a criação de universidades tenha sido postergada pelo Governo Federal até 1920, quando foi instituída a Universidade do Rio de Janeiro (URJ). Registra ainda, na década de 20, as discussões da Academia Brasileira de Educação e da Academia Brasileira de Ciências sobre concepções, funções e modelos de universidade. Analisa a Reforma de Ensino Superior de Francisco Campos (1931) e sua tendência centralizadora, registrando no período a criação da Universidade de São Paulo (1934) e da Universidade do Distrito Federal (1935), que expressam concepções distintas à proposta federal. Situa a instituição da Universidade do Brasil (1937) como modelo padrão, criada em 1920 (URJ) e reorganizada em 1931. Discute a universidade no pós-1945, destacando a tomada de consciência de sua situação por vários setores da sociedade, a partir dos anos 50, e, em especial, o papel do movimento estudantil no início dos anos 60 . Apresenta algumas medidas oficiais decorrentes dos acordos MEC/USAID, do Plano Atcon e do Relatório Meira Mattos. Analisa a Reforma Universitária de 1968 e suas consequiências para as instituições universitárias.

Palavras-chave: Universidade; Universidade no Brasil; Reforma Universitária.

${ }^{*}$ Livre Docente em Educação/PUC-Rio (1976). Coordenadora do PROEDES/FE/ UFRJ; Professora do Mestrado em Educação/FE/UCP e Pesquisadora 1 A do CNPq. 


\begin{abstract}
The article situates the attempts for the creation of universities in Brazil, from the time it was a Colony up to the Empire and the beginning of the Republic periods, which were unsuccessful. It registers the issuing of several legal apparatuses concerning higher education during the first Republic, even though the creation of universities as a whole had been postponed until 1920 by the Federal Government, year in which the University of Rio de Janeiro was created. It also acknowledges the discussions carried out within the Brazilian Academies of Sciences and of Education about the concepts, functions and models of university. The article analyses the Reform of Higher Education by Francisco Campos (1931) and discusses its centralizing approach. It pinpoints the creation of the University of São Paulo (1934) and that of the University Federal District (1935) at the same period, pointing out that those express different concepts to the federal proposal. It situates the University of Brazil (1937) as a model, created in 1920 under the denomination of URJ and recognized in 1931. The article also discusses the university after 1945, highlighting the awareness of its situation by several sectors of the society from the 50s onwards, particularly concerning the role of students movements in the beginnings of the 60s. It presents official measures taken as a result of the agreements MEC/USAID, of the Atcon Plan and of the Meira Mattos report. It discusses the University Reform of 1968 and its consequences for the university institutions.

Key-words: University; University of Brazil; University Reform.
\end{abstract}

\title{
Preliminares
}

Muito já se falou nesses últimos anos sobre a universidade no país. Diferentes interpretações foram apresentadas sobre a história dessa instituição e seus impasses, mas o desafio maior é transformá-la. Para tanto, faz-se necessário ter conhecimento de sua realidade, criação e organização, como funciona e se desenvolve, quais as forças que podem ser mobilizadas a fim de empreender as mudanças almejadas. Todavia, tal empreendimento não se faz sem relacionar essa instituição com o conjunto da sociedade, na ótica de sua dimensão política. O ponto de partida para qualquer discussão sobre universidade não poderá ser, portanto, "o fenômeno universitário" 
analisado fora de uma realidade concreta, mas como parte de uma totalidade, de um processo social amplo, de uma problemática mais geral do país.

Em decorrência de estudos e pesquisas realizados sobre a história da universidade brasileira, suas origens, desenvolvimento e impasses vivenciados até a Reforma Universitária de 1968, poder-se-ia observar que há um longo caminho a percorrer. Não se pretende afirmar, com isso, que algumas conquistas já não se fizeram sentir. Neste sentido, a universidade é convocada a ser o palco de discussões sobre a sociedade, mas não em termos puramente teóricos, abstratos. Deve ser o espaço em que se desenvolve um pensamento teórico-crítico de idéias, opiniões, posicionamentos, como também o encaminhamento de propostas e alternativas para solução dos problemas. Não resta dúvida de que essas tarefas constituem um aprendizado difícil e por vezes exaustivo, mas necessário.

No entanto, seria ingenuidade pensar que a crise e/ou impasses que as instituições universitárias enfrentaram até a década de 60 do século passado se restringem à universidade ou se circunscrevem aos limites do universo educacional. A crise da universidade pode ter relação íntima com o colapso de instituições existentes na sociedade brasileira, que não satisfazem ou não atendem aos interesses da velha ordem e, ao mesmo tempo, ainda não tinham assumido um papel atento a responder às necessidades emergentes. Uma questão se impõe: por que, no início do século XXI, nos preocuparmos em discutir a universidade no Brasil, situando sua história e os impasses por ela vividos até os anos 60 ?

Refletindo sobre essa questão, pode-se inferir que alguns desses impasses vividos pela universidade no Brasil poderiam estar ligados à própria história dessa instituição na sociedade brasileira. Basta lembrar que ela foi criada não para atender às necessidades fundamentais da realidade da qual era e é parte, mas pensada e aceita como um bem cultural oferecido a minorias, sem uma definição clara no sentido de que, por suas próprias funções, deveria se constituir em espaço de investigação científica e de produção de conhecimento. Produção essa que deveria procurar responder às necessidades sociais mais amplas e ter como preocupação tornar-se expressão do real, compreendida como característica do conhecimento científico, mas sem a falácia de respostas prontas e acabadas. 


\section{Tentativas de criação de universidade no Brasil}

A história da criação de universidade no Brasil revela, inicialmente, considerável resistência, seja de Portugal, como reflexo de sua política de colonização, seja da parte de brasileiros, que não viam justificativa para a criação de uma instituição desse gênero na Colônia, considerando mais adequado que as elites da época procurassem a Europa para realizar seus estudos superiores (MOACYR, 1937, p. 580-581). Desde logo, negou-a a Coroa portuguesa aos jesuítas que, ainda no século XVI, tentaram criá-la na Colônia. Em decorrência, os alunos graduados nos colégios jesuítas iam para a Universidade de Coimbra ou para outras universidades européias, a fim de completar seus estudos.

Entre as tentativas de criação de universidade no Brasil, ao longo dos anos, registra-se, no nível das intenções, a que constava da agenda da Inconfidência Mineira. Tentativas, sem êxito, continuam por mais de um século. Uma delas coincide com a transferência da sede da Monarquia para o Brasil. Portanto, não seria exagero inferir que Portugal exerceu, até o final do Primeiro Reinado, grande influência na formação de nossas elites. Todos os esforços de criação de universidades, nos períodos colonial e monárquico, foram malogrados, o que denota uma política de controle por parte da Metrópole de qualquer iniciativa que vislumbrasse sinais de independência cultural e política da Colônia (FÁVERo, 2000, p. 18-19). Importa lembrar ainda que, mesmo como sede da Monarquia, o Brasil consegue apenas o funcionamento de algumas escolas superiores de caráter profissionalizante. Ou seja, "o novo ensino superior nasceu sob o signo do Estado Nacional” (CUNHA, 1980, p. 62). A partir de 1808, são criados cursos e academias destinados a formar, sobretudo, profissionais para o Estado, assim como especialistas na produção de bens simbólicos, e num plano, talvez, secundário, profissionais de nível médio (CUNHA, 1980).

Nesse contexto, no ano da transmigração da Família Real para o Brasil é criado, por Decreto de 18 de fevereiro de 1808, o Curso Médico de Cirurgia na Bahia e, em 5 de novembro do mesmo ano, é instituída, no Hospital Militar do Rio de Janeiro, uma Escola Anatômica, Cirúrgica e Médica. Outros atos são sancionados e contribuem para a instalação, no Rio de Janeiro e na Bahia, de dois centros médico-cirúrgicos, matrizes das atuais Faculdades de Medicina da Universidade Federal do Rio de Janeiro (UFRJ) e da Universidade Federal da Bahia (UFBA) (villanova, 1948, p. 8). 
Em 1810, por meio da Carta Régia de 4 de dezembro, é instituída a Academia Real Militar, inaugurada em abril do ano seguinte. Foi nessa Academia que se implantou o núcleo inicial da atual Escola de Engenharia da UFRJ (VILlANOVA, 1948). Algumas modificações mais significativas parecem ocorrer com a criação dos cursos jurídicos, em 1827, instalados no ano seguinte: um em $1^{\circ}$ de março de 1828, no Convento de São Francisco, em São Paulo, e outro no Mosteiro de São Bento, em Olinda, em 15 de maio daquele ano. Segundo João Roberto Moreira, esses dois cursos passam a ter grande influência na formação de elites e na mentalidade política do Império. Constituem, sem dúvida, centros de irradiação de novas idéias filosóficas, de movimentos literários, de debates e discussões culturais que interessavam à mentalidade da época. E mais, tornam-se provedores de quadros para as assembléias, para o governo das províncias e também para o governo central (MOREIRA, 1960, p.53).

No Império, outras tentativas de criação de universidades se fizeram sem êxito; uma delas foi apresentada pelo próprio Imperador, em sua última Fala do Trono (1889), propondo a criação de duas universidades, uma no Norte e outra no Sul do país, que poderiam constituir-se centros de alta organização científica e literária.

Proclamada a República, outras tentativas são feitas. Cabe lembrar que, na Constituição de 1891, o ensino superior é mantido como atribuição do Poder Central, mas não exclusivamente. De 1889 até a Revolução de 1930, o ensino superior no país sofreu várias alterações em decorrência da promulgação de diferentes dispositivos legais. "Seu início coincide com a influência positivista na política educacional, marcada pela atuação de Benjamin Constant, de 1890-1891" (CuNHA, 1980, p. 132). Tal orientação é ainda mais acentuada com a Reforma Rivadávia Corrêa, em 1911, que institui também o ensino livre. Embora o surgimento da universidade, apoiado em ato do Governo Federal, continuasse sendo postergado, o regime de "desoficialização" do ensino acabou por gerar condições para o surgimento de universidades, tendendo o movimento a deslocar-se provisoriamente da órbita do Governo Federal para a dos Estados. Nesse contexto surge, em 1909, a Universidade de Manaus; em 1911 é instituída a de São Paulo e, em 1912, a do Paraná (міснецотто, 2006) como instituições livres.

Será oportuno observar, no entanto, que somente em 1915 a Reforma Carlos Maximiliano, por meio do Decreto $\mathrm{n}^{\circ} 11.530$, dispõe a respeito da instituição de uma universidade, determinando em seu art. $6^{\circ}$ : "O Governo Federal, quando achar oportuno, reunirá em universidade as Escolas Politécnica e de Medicina do Rio de Janeiro, incorporando a elas uma das 
Faculdades Livres de Direito, dispensando-a da taxa de fiscalização e dando-lhe gratuitamente edifício para funcionar".

Em decorrência, a 7 de setembro de 1920, por meio do Decreto ${ }^{\circ}$ 14.343, o Presidente Epitácio Pessoa institui a Universidade do Rio de Janeiro (URJ), considerando oportuno dar execução ao disposto no decreto de 1915. Reunidas aquelas três unidades de caráter profissional, foi-lhes assegurada autonomia didática e administrativa. Desse modo, a primeira universidade oficial é criada, resultando da justaposição de três escolas tradicionais, sem maior integração entre elas e cada uma conservando suas características. E mais, comparando a Exposição de Motivos do Ministro da Justiça e Negócios Interiores, Alfredo Pinto Vieira de Mello, com a forma simplificada e modesta, em termos de estrutura acadêmico-administrativa da primeira universidade oficial no país, resultaram desse cotejo sérias críticas. Entre outras, os comentários do educador José Augusto, em matéria publicada no Jornal do Brasil, de 24 de outubro do mesmo ano, sob o título "Regime Universitário III - O estado atual da questão no Brasil", na qual assinala: "O Decreto de 7 de setembro findo, com o qual o governo da República instituiu a Universidade do Rio de Janeiro, por julgar oportuno dar execução ao disposto no art. $6^{\circ}$ do Decreto $\mathrm{n}^{\circ} 11.530$, de 18 de março de 1915 , contém poucos artigos e trata a matéria da forma mais geral e vaga, de modo a não deixar no espírito de quem lê a noção exata e segura da verdadeira orientação a ser seguida pelo nosso Instituto Universitário".

Todavia, apesar das restrições feitas à criação dessa Universidade, cabe assinalar que, na história da educação superior brasileira, a Universidade do Rio de Janeiro é a primeira instituição universitária criada legalmente pelo Governo Federal. Não obstante todos os problemas e incongruências existentes em torno de sua criação, um aspecto não poderá ser subestimado: sua instituição teve o mérito de reavivar e intensificar o debate em torno do problema universitário no país. Esse debate, nos anos 20 do século passado, adquire expressão graças, sobretudo, à atuação da Associação Brasileira de Educação (ABE) e da Academia Brasileira de Ciências (ABC). Entre as questões recorrentes destacam-se: concepção de universidade; funções que deverão caber às universidades brasileiras; autonomia universitária e modelo de universidade a ser adotado no Brasil.

No que diz respeito às funções e ao papel da universidade, há duas posições: os que defendem como suas funções básicas a de desenvolver a pesquisa científica, além de formar profissionais, e os que consideram ser prioridade a formação profissional. Há, ainda, uma posição que poderia talvez vir a constituir-se em desdobramento da primeira. De acordo com 
essa visão, a universidade, para ser digna dessa denominação, deveria tornar-se um foco de cultura, de disseminação de ciência adquirida e de criação da ciência nova (ABE, 1929). Tais questões são também objeto de discussão na $1^{a}$ Conferência Nacional de Educação, realizada em Curitiba, em 1927, a partir da tese As Universidades e a Pesquisa Científica, apresentada por Amoroso Costa. A propósito, pode-se observar que, embora existissem posições divergentes, a tese defendida por Amoroso Costa, juntamente com o movimento liderado pela $\mathrm{ABE}$, ainda que não houvesse dentro da Associação um conceito unívoco de ciência, era introduzir a pesquisa como núcleo da instituição universitária (PAIM, 1982, p. 18).

No entanto, essa visão de universidade não chega a ser concretizada nos anos de 1920, nem na esfera federal, com a Universidade do Rio de Janeiro, nem na estadual, com a criação, em 1927, da Universidade de Minas Gerais, instituída, também, segundo o modelo da primeira.

\section{Os anos 30 e as propostas de Universidade}

Se a Primeira República é caracterizada pela descentralização política, a partir dos anos 20 e, sobretudo, após 1930, essa tendência se reverte, começando a se incrementar uma acentuada e crescente centralização nos mais diferentes setores da sociedade. Nesse contexto, o Governo Provisório cria o Ministério da Educação e Saúde Pública (14/11/1930), tendo como seu primeiro titular Francisco Campos, que, a partir de 1931, elabora e implementa reformas de ensino - secundário, superior e comercial - com acentuada tônica centralizadora. Trata-se, sem dúvida, de adaptar a educação escolar a diretrizes que vão assumir formas bem definidas, tanto no campo político quanto no educacional, tendo como preocupação desenvolver um ensino mais adequado à modernização do país, com ênfase na formação de elite e na capacitação para o trabalho.

Nessa linha, o Governo Federal elabora seu projeto universitário, articulando medidas que se estendem desde a promulgação do Estatuto das Universidades Brasileiras (Decreto-lei no 19.851/31) à organização da Universidade do Rio de Janeiro (Decreto-lei no 19.852/31) e à criação do Conselho Nacional de Educação (Decreto-lei no 19.850/31). Referindo-se às finalidades da Universidade, Campos insiste em não reduzi-las apenas à sua 
função didática. Para o Ministro, "sua finalidade transcende o exclusivo propósito do ensino, envolvendo preocupações de pura ciência e de cultura desinteressada" (CAmpos, 1931, p. 4). No plano do discurso, caberia à Faculdade de Educação, Ciências e Letras imprimir à universidade seu "caráter propriamente universitário", o que na prática não irá ocorrer. Analisando o Decreto no $19.852 / 31$, que dá nova organização à Universidade do Rio de Janeiro, observa-se que esse dispositivo é rico em pormenores sobre a citada Faculdade; contudo, não chega a ser imediatamente instalada pelo Governo Federal. Examinando-se o art. 196, verifica-se ainda que não se atribui a essa faculdade o caráter de unidade integradora dos diferentes institutos universitários, desde que sua existência não é obrigatória.

Analisando-se o Estatuto das Universidades Brasileiras, outras questões merecem registro. A primeira refere-se à integração das escolas ou faculdades na nova estrutura universitária. Pelo Estatuto, elas se apresentam como verdadeiras "ilhas" dependentes da administração superior. Outra questão relaciona-se à cátedra, unidade operativa de ensino e pesquisa docente, entregue a um professor. No Brasil, os privilégios do professor catedrático adquiriram uma feição histórica, apresentando-se o regime de cátedra como núcleo ou alma mater das instituições de ensino superior. E mais, a idéia de cátedra contida nesse Estatuto ganha força com as Constituições de 1934 e 1946, subsistindo até 1968, quando é extinta na organização do ensino superior, mediante a Lei ${ }^{\circ} 5.540 / 68$.

Na Reforma Campos, uma questão, ainda hoje desafiadora, diz respeito à concessão da relativa autonomia universitária como preparação gradual para a autonomia plena. Embora ressalte, na Exposição de Motivos sobre a reforma do ensino superior, não ser possível, naquele momento, conceder-se autonomia plena às universidades, a questão fica, a rigor, em aberto.

Apesar da tendência a uma centralização cada vez maior, reflexo da política autoritária adotada desde o início do Governo Provisório, houve iniciativas em matéria de educação superior, nesse período, que expressam posições contrastantes. Entre outras, podemos destacar: a criação da Universidade de São Paulo (USP), em 1934, e a da Universidade do Distrito Federal (UDF), em 1935. A USP, instituída por meio do Decreto ${ }^{\circ}$ 6.283/ 34 , surge com as seguintes finalidades:

a) promover, pela pesquisa, o progresso da ciência; b) transmitir, pelo ensino, conhecimentos que enriqueçam ou desenvolvam o espírito ou 
sejam úteis à vida; c) formar especialistas em todos os ramos da cultura, bem como técnicos e profissionais em todas as profissões de base científica ou artística; d) realizar a obra social de vulgarização das ciências, das letras e artes por meio de cursos sintéticos, conferências e palestras, difusão pelo rádio, filmes científicos e congêneres. (art. $2^{\circ}$ )

Com a promulgação da segunda Constituição Republicana (1934) e a eleição do presidente Getúlio Vargas pelo Congresso, havia a expectativa de que a democracia liberal fosse instituída no país. Mas, logo a seguir, as tendências centralizadoras e autoritárias recuperam a hegemonia. A abertura, proporcionada pela Revolução de 1930, passou a ser vista como um erro a ser corrigido. A partir de 1935, ampliam-se tendências centralizadoras e autoritárias, assegurando um clima propício à implantação do Estado Novo. Nos agitados meses desse ano, durante a gestão do prefeito Pedro Ernesto, foi instituída a Universidade do Distrito Federal (UDF), graças ao esforço, tenacidade e iniciativa de Anísio Teixeira. A UDF surge com uma vocação científica e estrutura totalmente diferente das universidades existentes no país, inclusive da USP, caracterizando-se como um empreendimento que procura materializar "as concepções e propostas da intelectualidade que, ligada à $\mathrm{ABE}$ e à $\mathrm{ABC}$, empunhara, na década anterior, a bandeira de criação da universidade como lugar da atividade científica livre e da produção cultural desinteressada" (ALMEIDA, 1989, p. 195). Fundada no Rio de Janeiro, capital da República, pelo Decreto Municipal $n^{\circ}$ 5.513/35, apesar de ter existido por período inferior a quatro anos essa instituição marcou significativamente a história da universidade no país, pela forma criadora e inovações com que a experiência se desenvolveu. Vale lembrar que, desde o início, apesar de grandes obstáculos, ela se apresenta não somente com uma definição precisa e original do sentido e das funções da universidade, mas também prevê os mecanismos que se fazem necessários, em termos de recursos humanos e materiais, para a consecução de seus objetivos.

$\mathrm{Na}$ inauguração dos cursos da UDF (31.07.1935), Anísio Teixeira, em discurso então proferido, ressalta:

\footnotetext{
A função da universidade é uma função única e exclusiva. Não se trata, somente, de difundir conhecimentos. O livro também os difunde. Não se trata, somente, de conservar a experiência humana. O livro também a conserva. Não se trata, somente, de preparar práticos ou profissionais, de
} 
ofícios ou artes. A aprendizagem direta os prepara, ou, em último caso, escolas muito mais singelas do que as universidades. (TEIXEIRA, 1998, p. 35)

Com essas palavras, Anísio chama a atenção para um problema fundamental: uma das características da universidade é a de ser um locus de investigação e de produção do conhecimento. E uma das exigências para a efetivação desse projeto era, sem dúvida, o exercício da liberdade e a efetivação da autonomia universitária. Mas, como pensar em autonomia universitária no limiar do Estado Novo?

Dentro do clima de inquietação e do estado de guerra decretado no país, o destino do fundador da UDF não poderia ser outro: afastamento de Anísio das funções públicas que vinha exercendo. Exonerado do cargo de Secretário de Educação a pedido, Anísio recebe de imediato apoio de colaboradores nos serviços de educação do Distrito Federal, alguns dos quais integrantes dos quadros da Universidade, também demissionários.

Apesar dos problemas enfrentados por essa Universidade, de 1935 a 1936 efetua-se a constituição de seu corpo docente e a organização de seus cursos. Com essa preocupação, buscam-se na Europa professores para aquelas áreas em que se considerava não haver, no Brasil, profissionais suficientemente preparados. Mas, o impedimento da UDF pelo Governo Federal era uma questão que se colocava de forma clara. A literatura, sobretudo a oficial, admite a incorporação dos cursos da UDF pela Universidade do Brasil. Na verdade, essa Universidade é extinta e seus cursos transferidos para a UB, em 1939, por meio do Decreto $n^{\circ} 1.063$, de 20 de janeiro. Em nome da disciplina e da ordem, o Ministro Capanema encaminha ao Presidente exposição de motivos que acompanha esse decreto, justificando, diria, a destruição da UDF (GC 36.09.18, doc. 13, série g, CPDOC/ FGV).

Será oportuno lembrar que, em 1935, o Poder Executivo elabora e encaminha ao Legislativo o Plano de Reorganização do Ministério da Educação e Saúde Pública (MESP). Na exposição de motivos que acompanha o projeto de lei, no item "Serviços relativos à educação", o Ministro Capanema assinala: "É à luz do critério de que a União não deve criar, manter e dirigir senão os serviços de significação nacional, que vamos enumerar quais hão de ser os serviços federais de educação" (BRASIL. MESP, 1935 , p. 26). Entre outros, o primeiro mencionado é a Universidade do 
Brasil. A respeito dessa instituição frisa: “À universidade, instituída, mantida e dirigida pela União, há de caber, sob todos os pontos de vista, uma função de caráter nacional" (BRASIL. MESP, 1935), ressaltando que, em primeiro lugar, ela deve tornar-se padrão, não querendo afirmar com isso "que todas as universidades do Brasil devam ser iguais à universidade federal" (BRASIL. MESP, 1935, p. 29).

Vale observar ainda que, ao instituir a Universidade do Brasil, a Lei ${ }^{\circ}$ $452 / 37$, que a criou, não faz referência ao princípio de autonomia em suas disposições gerais. Essa inferência procede quando se analisa o art. 27, o qual dispõe que tanto o reitor como os diretores dos estabelecimentos de ensino seriam escolhidos pelo presidente da República, dentre os respectivos catedráticos e nomeados em comissão. Por outro lado, torna-se expressamente proibida, aos professores e alunos da universidade, qualquer atitude de caráter político-partidário ou comparecer às atividades universitárias com uniforme ou emblema de partidos políticos. Essas determinações não seriam de estranhar, considerando-se o contexto em que elas são elaboradas.

\section{A Universidade no Brasil no pós-45}

Com a deposição do presidente Vargas, em outubro de 1945, e o fim do Estado Novo, o país entra em nova fase de sua história. Inicia-se um movimento para repensar o que estava identificado com o regime autoritário até então vigente. A chamada "redemocratização do país" é consubstanciada na promulgação de uma nova Constituição, em 16 de setembro de 1946, que se caracterizou, de modo geral, pelo caráter liberal de seus enunciados, como se pode observar no capítulo "Da declaração de direitos" e especialmente no que trata "dos direitos e das garantias individuais".

Cabe lembrar que, ainda no Governo Provisório instalado após a queda do Estado Novo, sendo Ministro da Educação Raul Leitão da Cunha, o Presidente José Linhares sanciona o Decreto-Lei no 8.393, em 17/12/1945, que "concede autonomia administrativa, financeira, didática e disciplinar à UB, e dá outras providências". Em cumprimento a esse dispositivo, o reitor passa a ser "nomeado pelo Presidente da República, dentre os professores 
catedráticos efetivos, em exercício ou aposentados, eleitos em lista tríplice e por votação uninominal pelo Conselho Universitário" (art. 17, § $1^{\circ}$ ).

Em cumprimento a esse dispositivo, a administração superior da Universidade passa a ser exercida não apenas pelo Conselho Universitário e pela Reitoria, mas também pelo Conselho de Curadores. No que tange à autonomia outorgada à Universidade do Brasil, dados obtidos da análise de documentos da instituição - Atas do Conselho Universitário, Atas da Congregação da Faculdade Nacional de Filosofia, etc. -, deixam perceber, de forma muito clara, que a autonomia administrativa, financeira, didática e disciplinar, outorgada à Universidade, não chegou a ser implementada. Tal inferência leva a reconhecer que, ontem como hoje, a autonomia outorgada às universidades não passa muitas vezes de uma ilusão, embora se apresente, por vezes, como um avanço.

No final dos anos 1940, como no início dos anos 50, começam a esboçar-se nas universidades algumas tentativas de luta por uma autonomia universitária, tanto externa como interna. Todavia, a situação é complexa. A propósito, Raul Bittencourt observa: "mesmo depois do Estado Novo, quando essa Universidade se torna autônoma por decreto, a situação não muda muito", acrescentando: é suficiente pensar no "DASP a intervir, dia a mais dia, na vida das universidades federais, com aspereza e inciência" (1946, p. 562).

Quanto à institucionalização da pesquisa científica, Antônio Paim, fazendo um balanço das instituições universitárias nos anos 80, observa: “(...) o impulso original que a pesquisa científica veio alcançar entre 1935 e 1945 leva a uma grande frustração na década de 50. Tornada instrumento de consolidação da universidade, que fora recusada sistematicamente ao longo de mais de um século, a pesquisa científica não chega contudo a assumir igualmente feição acabada (PAIM, 1982, p. 80).

Multiplicam-se as universidades, mas com predomínio da formação profissional, sem idêntica preocupação com a pesquisa e a produção de conhecimento. No entanto, será pertinente lembrar também que, de 1935 a 1945, a criação da Faculdade de Filosofia, Ciências e Letras da USP e da Escola de Ciências da UDF, posteriormente incorporada à Faculdade Nacional de Filosofia, tiveram o mérito de integrar desde o início estudiosos e cultores da ciência, que deixaram suas marcas, formando escola. Como bem assinala Paim, a Escola de Ciências da UDF e a Faculdade Nacional de Filosofia não apenas formaram os docentes das ciências exatas, mas prepararam diversos pesquisadores que passaram a integrar os quadros do Instituto Oswaldo Cruz, do Museu Nacional, do Departamento Nacional de 
Produção Mineral e do Instituto de Tecnologia. O intercâmbio com instituições estrangeiras, a participação em seminários e simpósios começam a fazer parte do trabalho dos cientistas e pesquisadores, já agora de forma institucional (PAIM, 1982, p. 80-81).

A partir da década de 50, acelera-se o ritmo de desenvolvimento no país, provocado pela industrialização e pelo crescimento econômico. Simultaneamente às várias transformações que ocorrem, tanto no campo econômico quanto no sociocultural, surge, de forma mais ou menos explícita, a tomada de consciência, por vários setores da sociedade, da situação precária em que se encontravam as universidades no Brasil. Essa luta começa a tomar consistência por ocasião da tramitação do projeto de Lei de Diretrizes e Bases da Educação Nacional, sobretudo na segunda metade dos anos 1950, com a discussão em torno da questão escola pública versus escola privada. Limitados inicialmente ao meio acadêmico, os debates e reivindicações deixam de ser obra exclusiva de professores e estudantes para incorporarem vozes novas em uma análise crítica e sistemática da universidade no país.

O movimento pela modernização do ensino superior no Brasil, embora se faça sentir a partir de então, vai atingir seu ápice com a criação da Universidade de Brasília (UnB). Instituída por meio da Lei no 3.998, de 15 de dezembro de 1961, a UnB surge não apenas como a mais moderna universidade do país naquele período, mas como um divisor de águas na história das instituições universitárias, quer por suas finalidades, quer por sua organização institucional, como o foram a USP e a UDF nos anos 30.

Nesse contexto, a participação do movimento estudantil se dá de forma muito densa, o que torna difícil analisar a história do movimento da Reforma Universitária no Brasil sem que seja levada em conta essa participação. ${ }^{1}$ Dos seminários e de suas propostas, fica evidente a posição dos estudantes, através da UNE, de combater o caráter arcaico e elitista das instituições universitárias. Nesses seminários são discutidas questões relevantes como: a) autonomia universitária; b) participação dos corpos docente e discente na administração universitária, através de critério de proporcionalidade representativa; c) adoção do regime de trabalho em tempo integral para docentes; d) ampliação da oferta de vagas nas escolas públicas; e) flexibilidade na organização de currículos (FÁvERO, 1994, p. 150151).

${ }^{1}$ A respeito consultar FÁVERO, M. L. A. A UNE em tempos de autoritarismo. Rio de Janeiro: Ed. UFRJ, 1995. 
Os seminários da UNE sobre a Reforma Universitária no início dos anos 60, de modo geral, colocam sempre o problema da universidade articulado com as reformas de base e questões políticas mais globais. Contudo, de abril de 1964 a 1967, as discussões no movimento estudantil passam a centrar-se sobretudo em dois pontos: a) revogação dos Acordos MEC/ USAID, e b) revogação da Lei Suplicy (Lei no 4. 464, de 9.11.1964), pela qual a UNE foi substituída pelo Diretório Nacional de Estudantes.

Ainda no início dos anos 60, algumas universidades, entre elas a Universidade do Brasil, elaboram planos de reformulação estrutural. No caso da UB, o Conselho Universitário designa, em fevereiro de 1962, uma comissão especial para tratar da questão. De seus trabalhos resulta o documento Diretrizes para a Reforma da Universidade do Brasil. Em junho de 1963, essas diretrizes são aprovadas pelo Conselho Universitário, mas, com o golpe militar de 1964, sua implantação é sustada.

Com base em estudos realizados na Universidade do Brasil, o Ministro da Educação, Raymundo Moniz Aragão - que havia sido um dos membros da referida comissão - dirige, em 1966, Aviso ao Conselho Federal de Educação (CFE), solicitando uma assessoria no sentido de formulação de dispositivo legal que corporificaria recomendações contidas no documento da UB. O anteprojeto emanado do CFE, com pequenas modificações, é transformado no Decreto-lei $n^{\circ} 53 / 66$. Logo a seguir, ainda com a participação do CFE, é formulado e expedido o Decreto-lei $\mathrm{n}^{\circ} 252$ que, segundo o Ministro, tratava-se de "explicativa de pontos menos claros no diploma anterior e revogativo de algumas disposições do Estatuto do Magistério (Lei $\mathrm{n}^{\circ}$ 4.881-A/65) que davam grande ênfase à cátedra" (ARAGÃO, 1968, p. 10).

No mesmo período, outras medidas oficiais são adotadas em relação à universidade. Três delas merecem destaque: o plano de assistência técnica estrangeira, consubstanciado pelos acordos MEC/USAID; o Plano Atcon (1966) e o Relatório Meira Mattos (1968). Concebida como estratégia de hegemonia, a intervenção da USAID na América Latina se processa de modo integrado, nos anos 60, em várias áreas e sob três linhas de atuação: assistência técnica; assistência financeira, traduzida em recursos para financiamento de projetos e compra de equipamentos nos EUA, além da assistência militar, concretizada pela vinda de consultores militares norteamericanos ao Brasil e do treinamento de militares brasileiros nos Estados Unidos, assim como do fornecimento de equipamentos militares (FÁvERO, 1994, p. 152-153).

Análise do Relatório da Equipe de Assessoria ao Planejamento do Ensino Superior (EAPES) deixa claro que sugestões nele contidas "se trans- 
formam em decisões do governo, vivamente empenhado na Reforma do Ensino Superior no Brasil" (EAPES, 1968, p. VIII). Quanto ao Plano Atcon, como ficou conhecido, trata-se de documento que resulta de estudo realizado pelo consultor americano Rudolph Atcon, entre junho e setembro de 1965, a convite da Diretoria do Ensino Superior do MEC, preconizando a implantação de nova estrutura administrativa universitária baseada num modelo cujos princípios básicos deveriam ser o rendimento e a eficiência (ATCON, 1966).

No documento Rumo à Reformulação Estrutural da Universidade Brasileira, editado pelo MEC em 1966, o consultor americano faz sugestões e recomendações que, no seu entender, tornariam possível a adequação do ensino superior e das instituições universitárias às necessidades do país. O projeto da Reforma Universitária incorpora algumas das propostas do Plano Atcon, como: defesa dos princípios de autonomia e autoridade; dimensão técnica e administrativa do processo de reestruturação do ensino superior; ênfase nos princípios de eficiência e produtividade; necessidade de reformulação do regime de trabalho docente; criação de centro de estudos básicos. Entre as propostas e recomendações feitas por Atcon encontra-se a criação de um conselho de reitores das universidades brasileiras. Este não deveria confundir-se com o Fórum de Reitores, já existente. ${ }^{2}$

Essa recomendação foi imediatamente posta em prática: em 29 de abril de 1966, é fundado o Conselho de Reitores das Universidades Brasileiras (CRUB), reconhecido como entidade de utilidade pública em 31 de julho de 1972, por meio do Decreto $\mathrm{n}^{\circ}$ 70.904. É pertinente lembrar que Rudolph Atcon não só foi convidado a organizar e estruturar o CRUB, mas nele trabalhou, como seu primeiro Secretário-Geral, de 1966 a 1968.

Em fins de 1967, preocupado com a "subversão estudantil", o Governo cria, por meio do Decreto $\mathrm{n}^{\circ}$ 62.024, comissão especial, presidida pelo General Meira Mattos, com as finalidades de: "a) emitir pareceres conclusivos sobre reivindicações, teses e sugestões referentes às atividades estudantis; b) planejar e propor medidas que possibilitassem melhor aplicação das diretrizes governamentais no setor estudantil; c) supervisionar e coordenar a execução dessas diretrizes, mediante delegação do Ministro de Estado". Do relatório final dessa Comissão, algumas recomendações também

${ }^{2}$ O Fórum de Reitores foi criado, em 1962, pelos próprios reitores, independente do Fórum Universitário instituído pela Portaria Ministerial no 67, de 27.02.1962. A propósito ver CUNHA, L. A. A Universidade crítica. Rio de Janeiro: Francisco Alves, 1983, p. 198. 
vão ser absorvidas pelo Projeto de Reforma Universitária: fortalecimento do princípio de autoridade e disciplina nas instituições de ensino superior; ampliação de vagas; implantação do vestibular unificado; criação de cursos de curta duração e ênfase nos aspectos técnicos e administrativos.

Com a proposta de fortalecer o princípio de autoridade dentro das instituições de ensino, pretendiam Meira Mattos e os membros da Comissão instaurar no meio universitário o recurso da intimidação e da repressão. Tal recurso é implementado plenamente com a promulgação do Ato Institucional $n^{\circ} 5$ (AI-5), de 13 de dezembro de 1968, e com o Decreto-lei $\mathrm{n}^{\circ}$ 477, de 26 de fevereiro de 1969, que definem infrações disciplinares praticadas por professores, alunos e funcionários ou empregados de estabelecimentos públicos ou particulares e as respectivas medidas punitivas a serem adotadas nos diversos casos.

\section{A Reforma Universitária de 1968: algumas questões}

No início de 1968, a mobilização estudantil, caracterizada por intensos debates dentro das universidades e pelas manifestações de rua, vai exigir do Governo medidas no sentido de buscar "soluções para os problemas educacionais mais agudos, principalmente dos excedentes". A resposta de maior alcance foi a criação, pelo Decreto $n^{\circ}$ 62.937, de 02.07.1968, do Grupo de Trabalho (GT) encarregado de estudar, em caráter de urgência, as medidas que deveriam ser tomadas para resolver a "crise da Universidade". No Relatório Final desse grupo aparece registrado que essa crise sensibilizou diferentes setores da sociedade, não podendo deixar de "exigir do Governo uma ação eficaz que enfrentasse de imediato o problema da reforma universitária, convertida numa das urgências nacionais" (RELATóRIO DO GRUPO DE TRABALHO, 1968, p. 17). E acrescenta: "o movimento estudantil, quaisquer que sejam os elementos ideológicos e políticos nele implicados, teve o mérito de propiciar uma tomada de consciência nacional do problema e o despertar enérgico do senso de responsabilidade coletiva" (RELATÓRIO DO GRUPO DE TRABALHO, 1968).

De acordo com o decreto que o instituiu, o Grupo de Trabalho tinha por objetivo “(...) estudar a reforma da Universidade brasileira, visando à sua eficiência, modernização, flexibilidade administrativa e formação de 
recursos humanos de alto nível para o desenvolvimento do país" (RELATÓRIO DO GRUPO DE TRABALHO, 1968, p. 15).

Apesar dos limites que o Grupo de Trabalho atribui às suas funções, Florestan Fernandes observa que o Relatório

\begin{abstract}
... contém, de longe, o melhor diagnóstico que o Governo já tentou, tanto dos problemas estruturais com que se defronta o ensino superior, quanto das soluções que eles exigem. Se a questão fosse de avanço 'abstrato' e 'teórico' ou verbal, os que participam dos movimentos pela reforma universitária poderiam estar contentes e ensarilhar suas armas. Entretanto, o avanço "abstrato" e "teórico" esgota-se [...] como se ele fosse uma verbalização de circuito fechado (FERNANDES, 1974, p.4 e 5).
\end{abstract}

Esse descompasso não é novo, mas pelo contrário, observa o sociólogo, "é parte normal de uma situação histórico-social em que a atuação conservadora se acha ameaçada e é compelida a assumir o controle político dos processos de modernização cultural e de inovação institucional" (FERNANDES, 1974). Nesses casos, o que prevalece é a preservação do monopólio do poder nas mãos das camadas conservadoras sem o avanço efetivo na solução dos problemas.

Entre as questões levantadas, o Relatório chama a atenção para o fato de a universidade brasileira estar organizada à base de faculdades tradicionais que, apesar de certos progressos, em substância, "ainda se revela inadequada para atender às necessidades do processo de desenvolvimento, que se intensificou na década de 1950 , e se conserva inadaptada às mudanças dele decorrentes". A respeito da expansão das instituições de ensino superior, ressalta-se que ela ocorre "por simples multiplicação de unidades, em vez de desdobramentos orgânicos". Complementando: "A universidade se expandiu mas, em seu cerne, permanece a mesma estrutura anacrônica a entravar o processo de desenvolvimento e os germes da inovação" (RELATÓRIO DO GRUPO DE TRABALHO, 1968, p. 19). E acrescenta: "podemos dizer que o sistema, como um todo, não está aparelhado para cultivar a investigação científica e tecnológica" (RELATÓRIO DO GRUPO DE TRABALHO, 1968, p.20), pois, “(...) mantendo a rigidez de seus quadros e as formas acadêmicas tradicionais, faltou-lhe a flexibilidade necessária para oferecer produto universitário amplamente diversificado e capaz de satisfazer às solicitações 
de um mercado de trabalho cada vez mais diferenciado" (RELATÓRIO DO GRUPO DE TRABALHO, 1968).

Apesar de o marco inicial da vasta legislação que estabelece medidas para a reestruturação das universidades brasileiras encontrar-se nos Decretos-leis $n^{\circ}$ s 53/66 e 252/67, somente a partir de 1968, como resultado dos trabalhos do GT e como desdobramento da ação iniciada em 1966, acrescida de outros atos, é que ganha sentido falar-se de uma legislação básica da Reforma Universitária.

Entre as medidas propostas pela Reforma, com o intuito de aumentar a eficiência e a produtividade da universidade, sobressaem: o sistema departamental, o vestibular unificado, o ciclo básico, o sistema de créditos e a matrícula por disciplina, bem como a carreira do magistério e a pósgraduação. Apesar de ter sido bastante enfatizado que o "sistema departamental constitui a base da organização universitária", não seria exagero observar que, entendido o departamento como unidade de ensino e pesquisa, a implantação dessa estrutura, até certo ponto, teve apenas caráter nominal. Por sua vez, embora a cátedra tenha sido legalmente extinta, em muitos casos foi apenas reduzida sua autonomia. A departamentalização encontra resistências desde o início da implantação da Reforma Universitária. Passadas mais de três décadas, observa-se ser o departamento, freqüentemente, um espaço de alocação burocrático-administrativa de professores, tornando-se, em alguns casos, elemento limitador e até inibidor de um trabalho de produção de conhecimento coletivo. Com a Lei no 9.394/ 96, o departamento não constitui mais exigência legal.

Quando ao vestibular unificado e classificatório, verifica-se que, no momento de sua implantação, exerceu dupla finalidade: racionalização no aproveitamento do número de vagas e admissão do ingresso não para determinado curso, mas para determinada área de conhecimento. A introdução do vestibular unificado como recurso para tornar mais racional a distribuição de vagas vai se revelar problemática poucos anos depois.

Após essa breve análise sobre a implantação da Reforma Universitária de 1968, constata-se que, a partir dos anos 80, surgem várias propostas para a reformulação das instituições universitárias. Será oportuno lembrar que tanto a reorganização do movimento estudantil, como a de outros grupos da sociedade civil, só irá se efetivar no final dos anos 70, com a abertura política e a promulgação da Lei da Anistia. Nas universidades públicas, após esta Lei se processa o retorno de vários professores afastados, compulsoriamente, após o AI-5.

No limiar da década de 80 , observa-se, da parte de significativo número de professores, a consciência de que o problema da universidade 
envolve não apenas aspectos técnicos, mas também um caráter marcadamente acadêmico e político, exigindo análise e tratamento específicos.

\section{Concluindo...}

Ocorre-me a percepção de que falar sobre a universidade no país e seus impasses até 1968 implica rever uma caminhada complexa, plena de obstáculos. Assim, numa tentativa de arrematar esse texto, direi: pareceme inadiável, nos dias atuais, reconstruir com seriedade e competência o trabalho universitário, vendo nele um empreendimento difícil, mas imprescindível, processo esse que deverá ser entendido e assumido como algo em permanente construção.

\section{REFERÊNCIAS}

ABE - ASSOCIAÇÃO BRASILEIRA DE EDUCAÇÃO. O Problema Universitário Brasileiro. Rio de Janeiro: A Encadernadora S.A., 1929.

ALMEIDA, M. H. T. Dilemas da institucionalização das Ciências Sociais no Rio de janeiro. In: MICELLI, S. (Org.). História das Ciências Sociais no Brasil. São Paulo: Vértice, Ed. dos Tribunais: IDESP, 1989, p. 188-226.

ARAGÃO, R. M. Introdução. A Reforma da Universidade Federal do Rio de Janeiro. Rio de Janeiro: UFRJ, 1968.

ATCON, R. P. Rumo à reformulação estrutural da universidade brasileira. Rio de Janeiro: MEC/DES, 1966.

AUGUSTO, J. Regime Universitário III. O estado atual da questão no Brasil. Jornal do Brasil, 24 de outubro de 1920.

BITTENCOURT, R. J. Autonomia Universitária. Revista Brasileira de Estudos Pedagógicos, v. 7, n. 21, p. 561-563, mar./abr. de 1946.

BRASIL. MESP. Plano de Reorganização do Ministério da Educação e Saúde Pública. Rio de Janeiro: Imprensa Nacional, 1935.

CAMPOS, F. Exposição de Motivos, apresentada ao Chefe do Governo Provisório, 
encaminhando o projeto de Reforma do Ensino Superior. In: Ministério da Educação e Saúde Pública. Organização Universitária Brasileira. Decretos nºs. 19.850, 19.851 e 19.852, de 11 de abril de 1931. Rio de Janeiro: Imprensa Nacional, 1931.

CAPANEMA, G. Exposição de Motivos de 28 de junho de 1938, encaminhando projetos de decretos-leis. GC 36.09.18, doc. 13, série g. CPDOC/FGV.

CUNHA, L. A. A Universidade Temporã. O Ensino Superior da Colônia à Era Vargas. Rio de Janeiro: Civilização Brasileira, 1980.

. A Universidade crítica. Rio de Janeiro: Francisco Alves, 1983.

EAPES. Relatório da Equipe de Assessoria ao Planejamento do Ensino Superior (Acordo MEC/USAID). Rio de Janeiro: MEC/DES, 1968.

FÁVERO, M. L.A. Vinte e cinco anos de reforma universitária: um balanço. In: MOROSINI, M. C. (Org.) Universidade no Mercosul. São Paulo: Cortez, 1994, p 149177.

UNE em tempos de autoritarismo. Rio de Janeiro: Editora UFRJ, 1995.

. Universidade e Poder. Análise Crítica/Fundamentos Históricos (1930-45). 2. ed. Brasília: Plano, 2000.

FERNANDES, F. Os dilemas da reforma universitária consentida. Debate e Crítica. São Paulo, n. 2, p. 1-42, jan./jun. 1974.

MICHELOTTO, M. R. UFPR:Uma universidade para a classe média. In: MOROSINI, M. C.(Org) A Universidade no Brasil: concepções e modelos. Brasília-DF: Inep, 2006, p. 73-84.

MOACYR, P. A Instrução e o Império. Subsídios para a história da educação no Brasil: 1854-1889. São Paulo: Companhia Editora Nacional, 1937, v. 2.

MOREIRA, J. R. Educação e desenvolvimento no Brasil. Rio de Janeiro: CLAPS, 1960.

PAIM, A. A busca de um modelo universitário. In: SCHWARTZMAN, S. (Org.). Universidade e Instituições Científicas no Rio de Janeiro. Brasília: CNPq, 1982.

RELATÓRIO DO GRUPO DE TRABALHO DA REFORMA UNIVERSITÁRIA, criado pelo Decreto nº 62.937/6. Rio de Janeiro: MEC/MPCG/MF, agosto, 1968.

TEIXEIRA, Anísio. Educação e universidade. Rio de Janeiro: Editora UFRJ, 1998.

TRIGUEIRO MENDES, D. Expansão do ensino superior no Brasil. Documenta, n. 91, p. 26-70, set. 1968.

VILLANOVA, José (Org.). Universidade do Brasil. Rio de Janeiro: Serviços dos Países S.A., 1948.

Texto recebido em 15 mar. 2006

Texto aprovado em 04 maio 2006 